\title{
Da filosofia crítica a crítica da filosofia universitária: provocações a partir da educação filosófica
}

\author{
From critical philosophy to the critique of university philosophy: provocations from \\ philosophical education
}

\author{
Tiago Brentam Perencini \\ Doutorando na Universidade Estadual Paulista Júlio de Mesquita Filho, Marília, São Paulo, Brasil. \\ tiagaobp@yahoo.com.br
}

Recebido em 18 de dezembro de 2017

Aprovado em 20 de junho de 2018

Publicado em 17 de agosto de 2018

RESUMO: O propósito geral deste artigo, pensado também à maneira de um exercício espiritual, é repensar o paradigma de crítica no interior do bloco saber-poder que envolve o campo discursivo sobre a formação do professor em filosofia no Brasil. Enuncio e persigo o seguinte problema: De que crítica se fala quando se fala da formação crítica nos discursos acadêmicos em filosofia e que potencialidades nos são dadas para praticar uma maneira outra de exercitá-la nesse projeto de formação? Lanço a hipótese de que o pressuposto da crítica tem sido concebido a partir de um horizonte estritamente epistemológico direcionado tanto para a adequação à normativa estabelecida, quanto para uma concepção restrita de cidadania. Argumento a partir de dois eixos diretivos: (1) Analiso arqueologicamente os enunciados de "crítica" dentro do Projeto Pedagógico do curso de Filosofia da Universidade de São Paulo, tendo em vista a ordem discursiva que essa instituição aventa para os demais centros universitários no país e (2) procuro movimentar outras acepções possíveis de crítica na junção ao pensamento de Michel Foucault. Essa disposição exige colocarmos à prova os conceitos, os procedimentos de pesquisa e as atitudes pelas quais trilhamos até o presente um tipo de crítica enunciada como julgamento e emancipação da consciência do outro no interior da Universidade. A partir da presente trilha percorrida, tenho compreendido a educação filosófica como potencialidade existencial, ética e estética que visa uma maior experimentação e transformação de si dentro do campo de formação do professor em filosofia no Brasil. Palavras-chave: Formação universitária em filosofia no Brasil; Educação filosófica; Crítica.

ABSTRACT: The general purpose of this article, also thought of as a spiritual exercise, is to rethink the paradigm of criticism within the knowledge-power block that surrounds the discursive field about philosophy teachers education in Brazil. I enunciate and pursue the following problem: What criticism are we talking about when we refer to critical education in academic discourses in philosophy? And which potentialities of practicing another way of exercising it in this education project are we given? I propose the hypothesis that the assumption of criticism has been conceived from a strictly epistemological horizon directed both to the adequacy to established norms, and to a strict conception of citizenship. I argue from two directive axes: (1) I perform an archeological analysis of the statements of "criticism" within the pedagogical project of the University of São Paulo's undergraduate program in Philosophy, 
considering the discursive order that this institution offers to other university centers in the country, and (2) I seek to move other possible meanings of criticism within Michel Foucault's thought. This arrangement demands that we test the concepts, the research procedures, and the attitudes through which we have hitherto pursued a kind of criticism enunciated as judgment and emancipation of the other's consciousness within the University. From this path taken, I have understood philosophical education as an existential, ethical and aesthetic potential that aims at greater experimentation and transformation of oneself within the field of philosophy teachers education in Brazil. Keywords: University philosophy education in Brazil; Philosophical education; Criticism.

\section{Da trajetória crítica no tempo presente: pensar desde a universidade e apesar da universidade}

Este texto se escreve à maneira de um exercício espiritual (HADOT, 2014) ${ }^{1}$ para repensar o papel da crítica como conceito, procedimento de pesquisa e atitude de formação do professor em filosofia no Brasil. Como exercício espiritual, não se deve esperar dele um tipo de arquitetônica teórica mais elevada, mas sim um relato sobre certo tipo de ver e de viver o mundo atrelado ao meu esforço de transformação de existência.

De maneira mais específica, objetivo neste tempo-espaço da escrita criar uma espécie de caderno de notas em dois movimentos. Primeiro, a tentativa de apontar certa deficiência no projeto de formação "crítica" que rege o campo discursivo nos cursos universitários de Filosofia no Brasil. Segundo algumas sugestões a partir de Michel Foucault para repensarmos outro tipo de crítica possível dentro de tais práticas universitárias. Foi no entremeio do planejado na instituição e do acontecido na vida que se potencializou em mim um tipo de experiência de abertura para conferir visibilidade à educação filosófica como potencial de formação crítica que visa a transformação e a experimentação de si.

$\mathrm{Na}$ tentativa de contribuir para a produção de pensamento que convoca a minha trajetória como pesquisador em filosofia e em educação no Brasil, persigo a hipótese de que o discurso "crítico, da crítica" dentro dos cursos de formação em filosofia no país tem sido concebido a partir de um horizonte estritamente epistemológico direcionado tanto para a adequação à normativa estabelecida, como para uma concepção restrita de cidadania.

Dito de modo específico, o discurso universitário da "crítica" dentro de tais cursos parece meramente incluído a um projeto de cidadania que visa a ordem discursiva de um sujeito livre, responsável e consciencioso para mera gerência "normal" do mercado de trabalho (USP, s/d; VATTER, 2016). Tenho ventilado nas pesquisas que caracterizam a minha trajetória de formação como o ensino de filosofia de cunho universitário degenerou o apreço à vida e se dirimiu a um apanhado metodológico, conceitual e técnico sobre autores clássicos na história da filosofia (PERENCINI e GELAMO, 2011, 2013; PERENCINI, 2015; PERENCINI e PAGNI, 2016) 2.

A motivação maior para repensar o ideário da crítica dentro da formação em filosofia deu-se a partir de minha percepção como egresso de um curso tradicional de filosofia e como doutorando em educação. Esta trajetória acadêmica sugere a percepção de que vivemos hoje certa crise epistemológica dentro do campo de formação universitária, que tem promovido não apenas uma ausência plena de sentido sobre a prática filosófica na universidade, mas certo esgotamento de possibilidades sobre o que 
significa ser professor de filosofia (ainda) hoje. É na oportunidade da crise que cabe repensar novos modos de vida que se atravessam para novas perspectivas críticas.

Para fundamentar este ensejo no presente texto, tomo como material de análise um arquivo que orienta a Universidade como instituição formadora em filosofia no Brasil: O Projeto Pedagógico do curso de Filosofia da USP, dada a sua importância histórica e geográfica dentro da produção de saberes-poderes que legitimaram a Universidade como instância formadora no Brasil. Pretendo, na análise do presente arquivo, promover certo tipo de leitura arqueológica a fim de diagnosticar como o pressuposto da crítica se restringe a uma ordem discursiva maior, que é a sua fundamentação como julgamento e hierarquia, degenerando outras experiências possíveis dentro da Universidade.

O sentido da leitura arqueológica será no propósito de identificar e descrever em que medida os enunciados da "crítica" apareceram no documento como conceito e projeto de formação. Tais inscrições possibilitarão uma compreensão maior sobre a presença da crítica enquanto uma formação discursiva que ampara os jogos de verdade sobre o saber universitário direcionado o eixo de formação para certo jogo de poder. A análise do saber não ocorre em termos de estrutura, de onde se poderia verificar uma verdade e uma falsidade, mas sim na identificação sobre o que foi dito verdadeiramente1 a seu respeito (PERENCINI, 2015).

O passo seguinte será conferir atenção a um tipo de crítica que não se insere no sujeito e na consciência moderna, mas que se embrenha na possibilidade de experimentação de si, na atenção ao tempo presente e na atitude como potencialidade ética para agir no mundo. Dado o curto espaço que acompanha a configuração deste texto, aterei-me a noção de crítica como compreendida em Michel Foucault a partir de uma conferência sua proferida em 27 de maio de 1978 e nomeada Qu'est-ce que la critique? [O que é a crítica? - 1990] como noção potencializadora para pensar outra formação possível, que flerta com a educação filosófica.

Ainda que este texto cumpra certa exigência teórica, vale a nota de que o recurso a Michel Foucault se entremeia a uma espécie de trilha perversa que já há alguns anos tenho percorrido dentro e fora da Universidade. Neste caminho, tenho sido povoado por certos intercessores visíveis e invisíveis que me tem alertado sobre um caminho outro em que a razão ou a linearidade do tempo não conseguiria chegar.

Da parte visível da Universidade, devo a minha gratidão a Pedro Angelo Pagni, orientador de doutoramento. A nossa relação cobra-me um olhar atento para a educação filosófica como tipo de campo transversal ao ensino de filosofia e que me tem conduzido para a busca de uma investigação ética e estética da intersubjetividade na formação do professor em filosofia no Brasil. Da parte invisível e exterior à Universidade, faz alguns anos que tenho sido atravessado como um a(u)tor que cruza com redes de afetos, fe(i) tiches4 e formações comunitárias que não se encontram no campo da educação formal5.

Tais tessituras de minha experiência, acompanhado da provocação filosófica encontrada em Michel Foucault, alertaram-me para a necessidade de pensar um outro tipo de crítica que não se materializa no primado da consciência, da razão ou do esclarecimento. Ensaiarei este pensamento neste texto, mesclando acontecimentos vitais e aportes teóricos no propósito de exercitar-me na invenção e procurando pistas para pensar o seguinte problema: De que 
crítica se fala quando se fala da formação crítica nos discursos acadêmicos em filosofia e que potencialidades nos são dadas para praticar uma maneira outra de exercitá-la nesse projeto de formação? Espero conseguir apontar como a crítica converteu-se no instrumento de saber que legitima poderes e que pouco contribui para pensarmos a relação entre a filosofia e a vida.

\section{A tradição crítica no projeto de formação em filosofia no Brasil}

O discurso da crítica acompanha toda a formação do estudante, professor e pesquisador em filosofia no Brasil. Isso pode ser verificado tomando como base o Projeto Pedagógico do curso de Filosofia da USP6, que será o arquivo central a ser analisado como diagnóstico de formação tanto por ele se configurar como um texto balizador das prioridades assumidas pela Instituição, quanto por ser a própria USP aquela que norteou historicamente o que se consagrou nomear "filosofia acadêmica" no país.

Encontramos logo nas primeiras linhas do presente arquivo a "formação técnica e crítica" alinhada como objetivo geral de formação:

A graduação em Filosofia visa a uma formação técnica e crítica
do estudante, por meio do estudo aprofundado da História
da Filosofia e dos temas que são os eixos da reflexão filo-
sófica, tanto os legados pela tradição, quanto os vinculados
as questões contemporâneas" (USP, s/d, p. 1, itálico meu).

Cabe a indagação sobre o que, afinal, se entende por crítica a partir da importância que confere a ela este "projeto de formação"?

Para responder a essa pergunta, identificarei os enunciados sobre a crítica, que estão presentes no Projeto Pedagógico, e descreverei certa regularidade discursiva que estabeleça algum tipo de continuidade entre os enunciados "crítica e formação em filosofia".

A observação primeira a ser feita é a de que a terminologia "crítica" aparece em 93 citações no arquivo, que conta também com os planos de ensino das disciplinas ministradas no curso, o que sugere a relevância do pressuposto crítico a que se dedica a formação institucional da filosofia. Parte das inscrições são notadas a obras e legados dos autores, sobretudo a Kant, como é o caso do referido exemplo: "uma certa vertente crítica inaugurada em meados do século XVIII e que culmina com a filosofia de Kant" (USP, s/d, p. 41), mas também há menções a um tipo de filosofia crítica a própria razão, como é o caso dos chamados "filósofos da diferença". Tais notações exercem pouco interesse para o nosso intento em encontrar certa regularidade discursiva, já que não estabelecem uma relação direta com o eixo de formação.

Há, contudo, outro tipo de acumulado entre enunciados que será de extrema importância para esta análise. O primeiro e mais recorrente deles diz respeito ao entrecruzamento entre os enunciados "crítica" e "capacidade", ou melhor, de que 
A capacidade docente decorre da pesquisa e de que o exercício da capacidade crítica, essencial ao filósofo, só se adquire no trato com as formas históricas do pensamento, consideradas na originalidade que as relaciona e diferencia. (USP, s/d, p. 1, itálico meu).

Substantivada como capacidade, a crítica aparece como o locus de chegada da maioridade, estágio de passagem do menor para o maior, de um não saber para um saber, daquele não dotado de conteúdo ou saber rigoroso, encontrado a partir das formas históricas do pensamento, mas que agora pode ser considerado eficiente na empresa que traz como finalidade a sua faculdade de julgar melhor.

$O$ fragmento abaixo contribui também para a sequência do que indiquei acima:

Formação significa antes de tudo a assimilação crítica da informação, e o desenvolvimento dessa capacidade é essencial para que o futuro docente/pesquisador possa refletir de maneira aprofundada tanto sobre a particularidade do seu trabalho quanto sobre a totalidade na qual este se insere. (USP, s/d, p. 2, itálico meu)7.

Nesses termos, a crítica confere ao formado em filosofia uma determinada posse do saber (assimilação crítica da informação) sempre atrelada a um grau mais elaborado e coerente (o desenvolvimento dessa capacidade) que deságua em uma reflexão específica (refletir de maneira mais aprofundada) para pensar tanto os aspectos inerentes ao seu trabalho, como o caráter mais amplo a que este se insere.

Dito nos termos do arquivo, trata-se de uma "rigorosa formação acadêmica e ou de uma formação mais ampla, que se poderia chamar de 'reflexão crítica'” (USP, s/d, p. 19, itálico meu), possibilitando assim que o estudante possa "ampliar seus parâmetros de pensamento, de maneira a efetuar a crítica presente" (USP, s/d, p. 19, itálico meu). Crítica como capacidade de julgar desde quando tomado o devido contato técnico com uma "rigorosa formação acadêmica", portanto.

A caracterização geral sobre as especificidades técnica e crítica dessa formação não podem ocorrer pela "importação não crítica de novidades europeias" (USP, s/d, p. 4, itálico meu), mas sim "de forma crítica e pluralista, a análise de problemas filosóficos centrais acerca do conhecimento e da ciência" (USP, s/d, p. 18, itálico meu), que atravessa todas às chamadas grandes áreas da filosofia, como é o caso da "perspectiva crítica em relação ao conhecimento produzido no âmbito das ciências humanas se desdobra nos aspectos da crítica da cultura, da crítica da sociedade e da crítica da ciência" (USP, s/d, p. 17, itálico meu), ou da "democracia como objeto de crítica, tanto no sentido de exame quanto no sentido de buscar reformá-la. De seu exame crítico nasceu uma sólida tradição de reflexão política" (USP, s/d, p. 45). A já referida rigorosa formação acadêmica ancora uma relevante produção de material para que o estudante amplie tecnicamente o seu parâmetro de pensamento e produza da crítica do presente (USP, s/d, p. 19): "semeadura crítica têm sido as traduções de textos de autores relevantes da reflexão estética" (USP, s/d, p.19, itálico meu), "cujas obras tornam possível entender os desdobramentos, prolongamentos, críticas e reformulações presentes na teoria social contemporânea” (USP, s/d, p. 17). 
A formação que trouxe por base a reflexão e o exame não se esgota no plano epistemológico, no sentido de averiguar um conhecimento ou uma teoria produzidos, tampouco se reduz ao cabedal de material produzido a partir de (e para uma) tradição acadêmica, mas empreende-se, sobretudo, para a formação de um ideal maior:

O Departamento de Filosofia tem como desideratum geral dedicar-se à formação de cidadãos competentes em suas avaliações morais e socialmente responsáveis e capazes de agir autonomamente, vale dizer, de maneira crítica. (p. 4) [...] tal processo de formação, visando, em especial, criar a necessária massa crítica, apresentou resultados positivos, embora de qualidade desigual. (USP, s/d, p. 11, itálico meu).

O projeto universitário visa, em última instância, criar a necessária massa crítica capaz de formar um tipo de cidadania competente em sua avaliação moral, socialmente responsável e apta para agir autonomamente. É possível, nos termos de uma análise arqueológica, estabelecer o enunciado de "crítica" tanto ao de (a) "exame e reflexão" como uma capacidade superior de julgamento a ser adotada pelo filósofo de formação acadêmica, quanto ao (b) da cidadania como "competência", "responsabilidade social" e "ação autônoma". Devemos, nessa esteira, escavar melhor a que ecos compreende o enunciado de "cidadania" no referido arquivo.

Em sentido amplo, cidadania corresponde à profissionalização, ou a integração produtiva na comunidade para o mundo do trabalho, tarefa empreendida pela instituição e pela sociedade. Nos termos do documento:

A profissionalização deverá ser vista, no seu melhor perfil, como um
vínculo entre a instituição e a sociedade, se entendermos que a prepa-
ração profissional necessita ser governada por parâmetros predomi-
nantemente sociais, a fim de que o profissional possa integrar-se
produtivamente na comunidade. No caso da universidade pública, essa
vinculaçãoentre profissionalismoe cidadania deveserorequisito básico
de preparação para o mundo do trabalho. (USP, s/d, p. 2, itálico meu).

Em sentido específico, aliando cidadania à formação universitária do egresso em filosofia:

O objetivo é dar ao futuro professor e pesquisador a formação compatível com a tarefa pedagógica, inclusive no que diz respeito às típicas dificuldades relativas ao ensino da disciplina no Ensino Médio, tarefa essa sempre entendida como trabalho de emancipação das consciências e da capacitação para uma cidadania efetiva. (USP, s/d, p.1).

A "capacitação para uma cidadania efetiva" liga-se, para o estudante que exercerá o ofício de professor da disciplina Filosofia no Ensino Médio, ao "trabalho de emancipação das consciências”. Não à toa, o mesmo arquivo atribui como 
Falência do ensino médio tanto público como privado e do consequente não cumprimento dos objetivos que deveriam ser realizados pelo ensino-médio, que não propicia mais a formação de um cidadão capaz de decidir autonomamente com base num conjunto de conhecimentos considerados básicos. (USP, s/d, p. 2 e 3, itálico meu).

Agora parece possível descrevermos a regularidade discursiva que atravessa crítica e cidadania como exercícios do graduado em filosofia, tomando nota o seu "projeto de formação", a partir da USP, instituição que se consolidou historicamente como ordem discursiva para boa parte dos demais cursos de filosofia no país.

A formação é considerada crítica quando o professor de filosofia, sujeito dotado de capacidade de reflexão e exame superior porque desfrutou da formação acadêmica a partir do seu contato rigoroso com o acumulado da História da Filosofia e dos temários clássicos eleitos e legados pela tradição Ocidental, cumpre o seu papel pedagógico de emancipador de consciências, isto é, consegue dotar o estudante de nível médio para o exercício efetivo de cidadania, que é sua adequação para os universais de "responsabilidade social e autonomia", características básicas e fundamentais para um perfil de profissionalização que corresponde ao ingresso no mercado de trabalho.

A regularidade discursiva envolvendo os enunciados da crítica e da cidadania no projeto de formação universitário ecoam a um propósito crítico mais amplo, do qual comungam tanto a tradição filosófica, como a filosófico-educacional que se instalou na recente história universitária brasileira (FREITAS, 2017, p. 199 e 200) e que resvala na tradição crítica europeia. No entender de Jean Masschelein:

\footnotetext{
Essa tradição crítica dominante e consagrada concebe a prática da filosofia (da educação) como uma espécie de investigação (suplementar) que tenta compreender, julgar e criticar a coerência, os valores, as observações, as reivindicações de conhecimento, a racionalidade, os objetivos, os princípios, as razões e os argumentos que estão presentes nos discursos e práticas educacionais (2014, p. 10).
}

Essa tradição tem concebido o trabalho filosófico fundamentalmente como um trabalho de julgamento e esclarecimento das suas pretensões de validade normativa ou epistemológica - ordenação, justificação, seleção, esclarecimento de conceito, interpretação ou explicação (MASSCHELEIN, 2014; FREITAS, 2017). Dito de maneira mais detalhada, a pesquisa filosófica dedica-se a construir um discurso no interior do sistema de pensamento de um filósofo considerado clássico pela tradição e isso reivindica para o pesquisador um papel de crítico como julgador "que se baseia em tomar distância e se desapegar da realidade que está sob minucioso exame, uma realidade que é, antes de tudo, considerada e vivida como objeto de conhecimento" (MASSCHELEIN, 2014, p. 11).

No Brasil, este pensamento permeou a partir da hipótese colonizadora (SANABRIA, 2014) de que, nas palavras de Paulo Arantes, "éramos um povo sem cabeça filosófica, [de modo que necessitávamos demonstrar] finalmente que reencontrávamos nossa verdade 
apresentando-nos mais modestamente como técnicos da inteligência filosófica" (1994, p. 21), conferindo à academia brasileira sua "vocação rigorosa de explicadores de texto". Como legado da tradição historiográfica no país, "ia ficando clara a conversão da filosofia, que obviamente não se ensina, numa questão de método" (idem, p. 18). E mais especificamente, de que "a filosofia era uma técnica de pensamento que nada tinha a ver com a vida" (idem, p. 55).

Em outra oportunidade, apontei como se deu arqueologicamente essa questão dentro do campo do ensino universitário de filosofia no Brasil desde a década de 1930 até 1968, anos de consolidação da academia no país (PERENCINI, 2017a). Com o propósito diferente para esse texto, nesse momento vale a pena mencionar que o entendimento da crítica como trabalho de julgamento e esclarecimento das suas pretensões de validade normativa ou epistemológica e a defesa desse tipo de crítica como objetivo geral do professor de filosofia para a formação da cidadania enquanto discurso de autonomia e responsabilidade a partir da transmissão do conteúdo filosófico para a profissionalização do estudante de nível médio traz consequências pouco profícuas para pensar filosoficamente a formação do professor em filosofia no Brasil.

Isso porque reduz a sua produção de pensamento ao campo do ensino de filosofia contido na instituição escolar, isto é, sobre a importância dessa disciplina para a formação da cidadania, do currículo e dos métodos a serem perseguidos para o melhor aprendizado dentro das finalidades mais amplas que repousam ora no discurso da preparação para o vestibular, ora na sua profissionalização para o mercado de trabalho. Desse ponto de vista, há pouco espaço para questionar a prática filosófica como um exercício de crítica à tecnicização do ensino, da deterioração da formação cultural na atualidade (PAGNI, 2016, p. 129; PAGNI, 2014) ou até mesmo como atitude de resistência à concepção de cidadania como posta dentro da democracia liberal. Na ambição de tencionar estas questões, temos nos ocupado em pensar um sentido ético-formativo mais amplo a partir da educação filosófica como um tipo de exercício crítico que excede o campo disciplinar e flerta com a experimentação e transformação de si.

\section{Re-pensar a crítica a partir da educação filosófica como atitude etopoiética}

A exigência de pensar as práticas de formação do professor em filosofia no Brasil a partir da educação filosófica flerta com a responsabilidade de operar um outro tipo de crítica como um exercício transversal que se estabelece em três deslocamentos indissociáveis: como conceito que não se retém à mera teoria, como procedimento de pesquisa que não toma a distância, mas se intimiza à experiência vivida e, finalmente, na atitude de transformar o presente como acontecimento filosófico. As contribuições de Michel Foucault serão oportunas para pensar outro tipo de crítica a partir da filosofia. Em essência, a tarefa da crítica no campo filosófico será pôr em cheque a própria pertinência de uma epistemologia, na tentativa de pensar certa ontologia precária do professor de filosofia cruzando os campos éticos e estéticos.

O "precário" aqui deve ser entendido como tudo aquilo que decide romper com convenções sociais, hábitos e valores já previstos dentro do campo de formação. É precário tudo aquilo que não é direcionado ao esperado pela sequência da cadeia de causas, de metas e de interesses em jogo a que requer a instituição (LAZZARATO, 2014, p. 23). A crítica como tarefa do professor de filosofia, nesse caso, viria no sentido não de emancipar consciências ou 
de formar para a cidadania circunscrita em seu registro liberal, mas sim como uma atividade de resistência a esses jogos discursivos que nada suspendem o curso habitual das coisas.

Vale lembrar que, de um ponto de vista procedimental, Foucault $(1996,1999,2002,2008)$ alerta que não existe separação entre conhecimentos, saberes e poderes, de tal maneira que uma analítica do poder pressupõe certa suspensão específica: "talvez devêssemos investigar as formas de resistência e as tentativas de dissociar estas relações" (FOUCAULT, 1995, p. 234). Isso é, o chamado para que o poder não seja analisado a partir do Estado ou de suas instituições disciplinares, mas sim pelas resistências que a ele se ventilam, se ampliam, se insurgem.

Disso depreende que a tarefa crítica não pode ser pensada como mero instrumento de conformação cidadã ao mercado ou formação para o conceito de autonomia, como parece requerer o projeto de formação universitário no Brasil, mas é justamente aquilo do qual não se pode policiar ou regulamentar e, nesse caminho, oferece uma função não ordenadora. Nas palavras de Butler, "crítica é sempre crítica de uma prática institucionalizada, um discurso, uma espiteme, uma instituição" (2013, p. 159), tarefa de inconformidade de um para com o outro, portanto.

Conhecemos o que podemos conhecer? Tal pergunta joga luz no exercício de transposição, em filosofia, da tarefa conceitual como princípio de originalidade e rigor, para a crítica como uma prática investigativa em que, como sugere Butler:

O principal não é remeter [esta] prática a um contexto epistemológico pré-dado. É, antes, firmar a crítica como uma prática que expõe os limites do próprio horizonte epistemológico, fazendo com que os contornos desse horizonte apareçam, por assim dizer, pela primeira vez no seu limite. (2013, p. 166).

Afinal, cabe o alerta de Foucault:

Se tomarmos uma escala maior e se escolhermos, como marcos, disciplinas como gramáticas, ou a economia, ou o estudo dos seres, o jogo dos conceitos que vemos aparecer não obedece a condições tão rigorosas: sua história não é pedra por pedra, a construção de um edifício. (2008, p. 62).

Mas se transformam, recortam, apagam e reaparecem no curso de uma história a partir dos jogos de verdade. São esses jogos de verdade que tem de serem colocados à prova a partir da exposição dos limites do horizonte epistemológico no campo filosófico enquanto certa atitude crítica.

A título de (auto) provocação, quando referimos a nós mesmos como tradição acadêmica no tempo presente, vale a pena perguntar: mobilizamos conceitos que tratam efetivamente da vida, para melhorar a vida daqueles que não comungam do métier interno à Universidade, ou restringimo-nos ao exercício de validar este ou aquele campo e teoria do qual somos parte; nós, os iniciados da e na tradição? A partir do horizonte foucaultiano, o conceito nos cobra outro tipo de exigência, que é o gesto de problematizar justamente os espaços de verdade aos quais circulam tanto os conceitos quanto a nós mesmos. 
Nesse sentido, é preciso concebermos a crítica no interior da formação institucional em filosofia como uma experiência de acontecimentalização que relaciona tanto os conceitos como os procedimentos de pesquisa à tarefa de percepção sobre os mecanismos de coerção (conjuntos legislativos, regulamentos, fenômenos de autoridade) aos conteúdos de conhecimento. Diferente da formação requerida pelo Projeto Pedagógico da Universidade de São Paulo, que objetiva a "formação técnica e crítica do estudante, por meio do estudo aprofundado da História da Filosofia e dos temas que são os eixos da reflexão filosófica" (USP, s/d, p. 1, itálico meu), Foucault alerta-nos para um tipo de diagnóstico que visa justamente a mostrar os limites deste tipo de formação para repensar outras formas de vida na atualidade. Partindo desta provocação:

O que se busca então não é saber o que é verdadeiro ou falso,
fundamentado ou não fundamentado, real ou ilusório, científico
ou ideológico, legítimo ou abusivo. Procura-se saber quais são
os elos, quais são as conexões que podem ser observadas entre
mecanismos de coerção e elementos de conhecimento, quais jogos
de emissão e de suporte se desenvolvem uns nos outros, o que
faz com que tal elemento de conhecimento possa tomar efeitos
de poder afetados num tal sistema a um elemento verdadeiro ou
provável ou incerto ou falso, e o que faz com que tal procedimento
de coerção adquira a forma e as justificações próprias a um elemento
racional, calculado, tecnicamente eficaz. (FOUCAULT, 1990, p. 14).

A exposição dos limites do horizonte epistemológico permite ao sujeito o direito de interrogar a verdade sobre os seus efeitos de poder e o poder sobre os seus discursos de verdade (FOUCAULT, 1990, p. 5). Logo, essa articulação direciona para a crítica não apenas uma tarefa conceitual e de procedimento de pesquisa, mas uma articulação à atitude do professor e pesquisador em filosofia, que se entrelaça aos campos existencial e ético.

Dentro das contribuições foucaultianas, a ética evoca certa existencialidade porque só pode ser compreendida a partir da autotransformação daquele que pratica a virtude. Virtude como ato de coragem, ato de agir sem garantias, que arrisca o sujeito contra os limites da ordenação (BUTLER, 2013, p. 176). Uma formação em filosofia a partir da educação filosófica flerta, então, com uma formação virtuosa no campo existencial e ético que preludia o ato de coragem, este agir sem garantias que arrisca o sujeito contra os limites da ordenação afirmado pelos jogos de verdade epistemológica e institucional.

Foucault está ocupado justamente com a junção entre conhecimento e o poder para dar visibilidade àqueles que não se curvam à instituição. Uma formação existencial e ética em filosofia visa à transformação desse "eu-professor-pesquisador-filósofo", que se contorce com as regras de conduta ditadas pela instituição, mas que também resiste a elas em uma ação sem garantias. A transformação desse "eu" é também precária porque enfrenta às figuras de autoridades postas de antemão.

A educação filosófica pensada a partir dos campos éticos e existencial como atitude de dizer não reverbera na seguinte definição foucaultiana de crítica: "a arte da servidão voluntária, aquela da indocilidade refletida. A crítica teria por função o desassujeitamento no jogo do que se poderia chamar, em uma palavra, de política da verdade" (1990, p. 5, itálico meu). Tratamos, então, 
de uma formação crítica que, muito embora mobilize a técnica, está longe de ser um instrumento cognoscente e previsível justamente porque é uma arte. A arte precária de não ser governado tanto assim, de fazer de outro modo, de experimentar outros campos, corpos, objetos e sujeitos. Este gesto educativo é ético porque exige novas práticas de formação como estilizações não moralizantes. É poética e dramática porque se trata de uma arte de existência que convoca o sujeito como criador e criatura, obra e autor (BUTLER, p. 177) que age sem garantias, precariamente.

Nessa esteira dos corpos, as linhas entre o formador e o formado, entre o que se forma e é formado, é difícil de ser traçada, pois não é nem prévia, nem previsível, mas sim acontecimental, isto é, uma atitude etopoiética que esteja atenta para o que nos acomete enquanto sujeitos partilhantes de uma experiência orientada tanto para o nosso cuidado como sujeitos, mas também para o cuidado do outro e do mundo em que vivemos.

Como estudantes e formadores em filosofia, é nossa a tarefa de inventar uma experiência educativa que não seja pautada na proibição e na interdição, mas que proporcione uma maior atenção para com o mundo hoje habitado na partilha de nossa sensibilidade comum. Como já referido, neste pequeno ensaio de pensamento, procurei apresentar uma urgência de repensar o postulado de formação a partir da crítica não como julgamento, mas em favor de uma prática ética, estética e existencial que exige de nós a disposição para sair do nosso lugar comum de pensamento sobre o que são os conceitos, as tarefas procedimentais de pesquisa e os gestos de formação.

Pouco nos atentamos para o aprendizado a partir dos sinais da vida, mas tenho estabelecido um profundo exercício de atenção das ações promovidas ao longo de meu ciclo vital, que pouco configuram o que consideramos "resultados de uma pesquisa". Penso que a formação do professor em filosofia, além de não se restringir ao ensino dessa disciplina, parece se constituir de outros elementos que transcendem a própria Universidade enquanto instituição. A fim de contribuir em tom de desfecho deste exercício espiritual, tomando a minha experiência como exemplo, formei-me apesar do modo como eram concebidas as práticas universitárias em filosofia na Instituição Universitária pela qual fui formado, flertando com o início prematuro na experimentação como professor de filosofia, nos laços afetivos que me uniam nos eventos e grupos de estudos e também na esfera de atuação política e artística a que me envolvi durante anos. Este percurso formativo emergiu-me a percepção de que a formação do professor em filosofia se compõe de um campo ético, afetivo e subjetivo que transcende o próprio ensino e a instituição, mas que é pouco ou nada trabalhado nas práticas universitárias de formação.

Tenho encontrado na educação filosófica uma abertura que não direciona a filosofia como mera disciplina escolar, restrita ao campo da técnica, do ensino e da aprendizagem de conteúdos e de métodos a partir da história ou do temário clássico. Sigo o meu empenho em favor de uma formação mais arriscada, que faça a arte prevalecer sobre as prescrições morais e epistemológicas. Esta espécie de exercitação espiritual como prática só encontra sentido à medida que assumo os riscos de enunciar novas possibilidades de formação que provocam e convocam a tomarmos uma outra direção na contemporaneidade, tempo de crise, tempo presente, possível de se fazer de outro modo. 


\section{Referências}

ALBUQUERQUE, M. B. B. Epistemologia da ayahuasca e dissolução das fronteiras natureza/cultura da ciência moderna. Fragmentos de Cultura. v. 24, n. 2, p. 179-193, abr./jun. Goiânia, 2014.

ARANTES. P. E., Um departamento francês de ultramar: estudos sobre a formação da cultura filosófica uspiana. Rio de Janeiro: Paz e Terra, 1994.

BUTLER, J. O que é a crítica? Um ensaio sobre a virtude de Foucault. Cadernos de Ética e Filosofia Política. № 22, p. 159-179, São Paulo, 2013.

DREYFUS, H.; RABINOW, P. Michel Foucault: uma trajetória filosófica (para além do estruturalismo e da hermenêutica). Trad. Vera Porto Carrero. Rio de Janeiro: Forense Universitária, 1995.

FOUCAULT, M. O que é a crítica? Trad. Gabriela Lafetá Borges, Rev. Wanderson Flor Nascimento. Vol. 82, n 2, pp. 35 - 63, abr/jun 1990. Disponível em: http://michel-foucault. weebly.com/uploads/1/3/2/1/13213792/critica.pdf Acesso em: 21 mai 2017.

A ordem do discurso: aula inaugural no Collège de France pronunciada em dois de dezembro de 1970. Trad. Laura Fraga de Almeida Sampaio. São Paulo: Loyola, 1996.

As palavras e as coisas: uma arqueologia das ciências humanas. Trad. Salma Tannus Muchail. São Paulo: Martins Fontes, 1999.

A verdade e as formas jurídicas. Rio de Janeiro: NAU, 2002.

A arqueologia do saber. Trad. Luiz Felipe Baeta Neves. 7.ed. Rio de Janeiro: Forense Universitária, 2008.

FREITAS, A. S. A pesquisa em filosofia da educação como (des)encontros entre Filosofias da Educação. In: BANNEL, R. I. et al. Filosofia da Educação: entre a formação de educadores e a qualificação profissional, São Paulo: Cortez: 2017.

HADOT, P. Exercícios espirituais e filosofia antiga. São Paulo: É realizações, 2014.

LATOUR, B. Reflexão sobre o culto moderno dos deuses fe(i)tiches., trad. Sandra Moreira, Bauru: Edusc, 2002.

LAZZARATO, M. Signos, máquinas, subjetividades. Trad. Paulo Domenech Oneto, Colab. Hortência Lancastre. $1^{\text {a }}$ ed. São Paulo: Edições Sesc São Paulo, n-1 edições, 2014.

MASSCHELEIN, J. Filosofia como (auto) educação para fazer a voz do pedagogo ser ouvida. .; SIMONS, M. A pedagogia, a democracia, a escola. $1^{\text {a }}$ ed. Belo Horizonte: Autêntica Editora, 2014.

PAGNI, P. A. O sentido ético da dramática de si e o significado político da poética da diferença na pragmática do ensino: considerações à luz de Foucault. Espaço Pedagógico, v. 21, n. 1, p. 80-96, jan./jun., Passo Fundo, 2014. 
. Considerações sobre a educação filosófica no ensino médio e o seu sentido éticoformativo. SEVERINO, A. J.; LORIERI, M. A.; GALLO, S (orgs). O papel formativo da Filosofia. Jundiaí, Paco Editorial, 2016.

PERENCINI, T. B.; GELAMO, R. P. O “lugar” do conhecimento e da experiência no aprendizado da filosofia. Marília: Pibic/cnpq, 2011. 70 p.

. Ensino de Filosofia no Brasil: A recepção e o seu debate nos periódicos brasileiros. Marília: Fapesp, 2013. 177 p.

PERENCINI, T. B. Uma arqueologia do ensino de filosofia no Brasil: Formação discursiva na produção acadêmica de 1930 a 1968. São Paulo: Cultura Acadêmica, $2017 a$.

. O enunciado no pensamento arqueológico de Michel Foucault, Kínesis, v.VII, nº 15, p. 135-150, Marília-SP, 2015.

A formação do professor em Filosofia no Brasil: restrição de pensamento e testemunho. Filosofia e Educação. V.9, n.2, p. 23 - 47, jun. set., 2017b.

SANABRIA DE ALELUIA, J. R. A invenção do filósofo ilustrado. Notas arqueológicas sobre o ensino de filosofia no Brasil. São Paulo, Cultura Acadêmica, 2014.

UNIVERSIDADE DE SÃO PAULO (USP). Projeto pedagógico (De acordo com a Deliberação da CEE n 99, de 24/05/2010). Disponível em: http://filosofia.fflch.usp.br/departamento/projetoacademico. Acesso em: 08/09/2016. Quinquênio 2012 - 2016.

VATTER, M. Foucault e Hayek: Lei republicana e sociedade civil liberal. NALLI, M; MANSANO, S. R. V. (org). Michel Foucault: desdobramentos. $1^{\text {a }}$ ed, Belo Horizonte: Autêntica Editora, 2016.

VEYNE, P. Foucault: seu pensamento, sua pessoa. Trad. Marcelo Jacques de Morais. Rio de Janeiro: Civilização Brasileira, 2011.

\section{Notas}

1 Tomarei emprestada a acepção de exercícios espirituais, de Pierre Hadot (2014), que nos provoca a pensar a vida filosófica como uma proposta ao desenraizamento da vida cotidiana mediante práticas que favorecem uma conversão, uma mudança total de visão, de estilo de vida. Nesse sentido, a filosofia antiga se fez não em vias de uma construção teórica, mas como uma formação de si, uma maneira de viver e de ver o mundo, atrelada ao esforço de transformação da própria existência daquele que estabeleceu contato com as práticas cotidianas filosóficas. Tenho perseguido a filosofia como terapêutica partindo desse ponto de vista.

${ }^{2}$ Referências as investigações: O "lugar" do conhecimento e da experiência no aprendizado da filosofia, sob a orientação de Rodrigo Pelloso Gelamo, de modalidade PIBIC/CNPq (Edital 2010/11 - Processo 145202/20100). Também a pesquisa intitulada $O$ Ensino de Filosofia no Brasil: A recepção e o seu debate nos periódicos brasileiros, sob o fomento da FAPESP [Processo 2011/21785-0], na modalidade Iniciação Científica, investiguei a recepção do debate sobre o ensino de Filosofia em mais 10 periódicos brasileiros. No mestrado, desenvolvi a pesquisa nomeada O ensino de filosofia no Brasil: A sua formação discursiva no contexto universitário de 1930 
a 1968 [FAPESP Processo: 2012/21672-4], onde procuro fazer um resgate da formação discursiva do debate acadêmico do ensino de filosofia nos anos formadores da Universidade brasileira. $O$ material de análise foram 41 periódicos das áreas de Educação e de Filosofia publicados durante o período de 1930 a 1968. A pesquisa que Pagni e eu temos efetuado no momento é o doutoramento em andamento. Partimos da hipótese de que a formação acadêmica do professor em filosofia no Brasil foi amplamente efetuada a partir da institucionalização da filosofia na esfera escolar, restringindo a sua exercitação ao aparato de ensino que se fundamenta na concepção técnica de história, leitura e escrita de texto, em que aprender filosofia torna-se o reconhecimento, aplicação e avaliação de tais especificidades. Este projeto não constará nas referências bibliográficas, pois a pesquisa está na fase de reelaboração de projeto e não há ainda uma divulgação expressiva de resultados.

${ }^{3} \mathrm{O}$ analista do saber recorre ao discurso para efetivar o seu ofício. Acerca do discurso, não há verdadeiro e falso, mas um dizer verdadeiro, que pode ser definido com Paul Veyne (2011, p.25) na seguinte passagem: "Os discursos variam ao longo do tempo; mas a cada época eles passam por verdadeiros. De modo que a verdade se reduz a um dizer verdadeiro, a falar de maneira conforme ao que se admite ser verdadeiro e se fará sorrir um século mais tarde".

${ }^{4}$ Termo caricato empregado por Bruno Latour (2002), que sintetiza a combinação de "feito" (fait) e "fetiche" (fétiche), em francês, faitiches, mostrando, paradoxal e ironicamente, que a modernidade também estabeleceu os seus feitiços e os fetiches perante os objetos e rituais.

${ }^{5}$ Por certa gratidão espiritual a estes acontecimentos que a vida me trouxe, faço menção especial à formação nada oficial que tive quando fazia parte de uma trupe de palhaços, ou através dos educadores populares (terapeutas integrativos, benzedeiras, raizeiros, magos, bruxos, etc.) com quem cruzei, ou dos círculos Sagrados que já participei, ou mediante a experiência com a planta sagrada e professora ayahuasca, que me atentou para outras formas de conhecer e de me relacionar com a vida, o real, o humano e o imaginário (ALBUQUERQUE, 2014).

${ }^{6}$ De acordo com a Deliberação CEE n99, de 24/05/2010. Documento composto por 123 páginas e que compreende também os planos de ensino das disciplinas ministradas na referida instituição. Muito embora a vigência do documento conste entre o quinquênio de 2012 a 2016, não se encontra ainda atualizado na página da instituição até a presente escrita deste texto. $O$ documento pode ser encontrado na íntegra a partir deste endereço eletrônico: http://filosofia.fflch.usp.br/departamento/projetoacademico.

${ }^{7}$ Vale a nota de que existe uma referência muito similar a esta na mesma página do referido arquivo: "desenvolvimento dessa capacidade é essencial para que o futuro docente/pesquisador possa refletir de maneira aprofundada tanto sobre a particularidade do seu trabalho quanto sobre a totalidade na qual este se insere" (USP, s/d, p. 2, itálico meu).

\section{Correspondência}

Tiago Brentam Perencini - Rua Hygino Muzy Filho, 737, Mirante, Universidade Estadual Paulista Júlio de Mesquita Filho, Faculdade de Filosofia e Ciências - Campus de Marília, Departamento de Didática, CEP 17.525-900, Marília, São Paulo, Brasil.

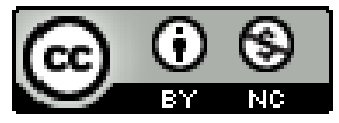

This work is licensed under a Creative Commons Attribution-NonCommercial 4.0 International (CC BY-NC 4.0) 